\title{
東支那海のまき網漁場についで
}

\author{
森勇 \\ (1962 年 12 月 1 日受理)

\section{FISHING GROUNDS BY THE PURSE-SEINE IN THE EAST CHINA SEA.}

\author{
Isamu MoRI**
}

\begin{abstract}
The present author has studied on the hydrographic conditions in jack mackerel and mackerel fishing grounds by the purse-seine in the East China Sea.

The most important fish species of the catches is the jack mackerel, but the mackerel also caught together with the jack mackerel. The water temperature in well catch conditions is from $13^{\circ} \mathrm{C}$ in winter to $21^{\circ} \mathrm{C}$ in spring and the chlorinity ranges from $17.50 \mathrm{Cl} \%$ to 19.30 $\mathrm{Cl} \%$.

In view point of the oceanographic structure, it seems that the most important purse-seine fishing grounds for the jack mackerel cover the sea areas which are intermediate zones between the cold water masses extruded from the Yellow Sea and the warm Kuroshio Current in the East China Sea.

Especially the sea areas near the coastal water masses in the intermediate zones are valuable as the main fishing grounds in spring.
\end{abstract}

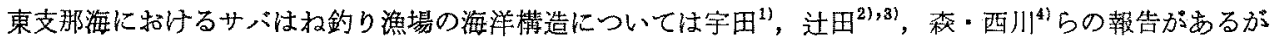
1958 年春, 開発されたまき網漁場について報告されたるのはない。筆者は 1958＇61 年に行なつた東支那 海まき網漁場調查の結果から一，二の知見を得たので報告する。

\section{1. 東支那海の海況とまき網漁場開発の释過}

東支那海の海洋構造の根幹をなすものは，南西諸島西方の陸概绿辺奇りを北上する黑潮系暖流水塊，ソコ トラロック西方から南下する黄海冷水塊, 楊子江沖合に中心を有し陸棚の上風を東進する大陸沿岸水堎の三 者であるが、暖流水塊々黄海冷水塊，ならびに大陸沼岸水の接触するのは通常陸棚の縁㲽付近であり，海沉 の変動が激しい。

東支那海に却けるまき網漁場の開発は 1950 年以降当業者, 研究機関の手により進められ，1958 年春クチ ビノ七漁場, 1959 年秋黄海漁場が開発されたが, Table 1 に示した長崎魯市場の水揚状況から知られるよ

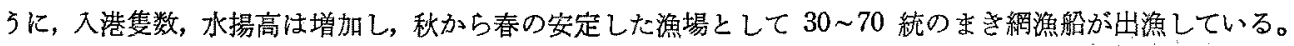

2. まき網漁場の水温・塩素量

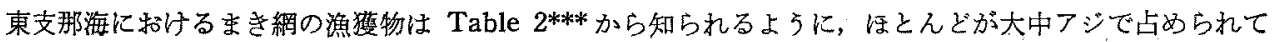

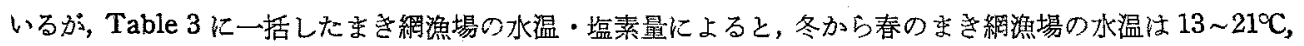

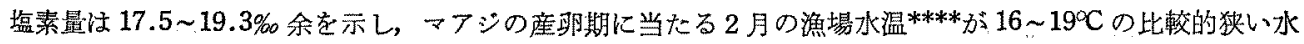
温範四にあることが知られ，Table 4 亿示したクチビノセ漁場でも水温 $15 \sim 19{ }^{\circ} \mathrm{C}$ を示す海域て好漁をみて

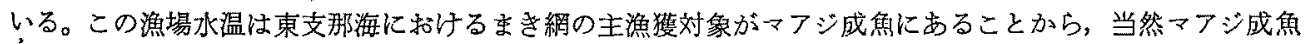
の適水温を示すことが予測されるとこるであるが，マアジ成魚の適水温を $13 \sim 18^{\circ} \mathrm{C}$ (産邸檤水温 $16 \sim 17^{\circ} \mathrm{C}$ )

* 長崎県水産試験場業緽

**長崎県水産試験場 (Nagasaki Pref. Fish. Exper. St., Nagasaki, Japan).

**** 農林省: 農林水産統計報告, 35 45 (1960).

***** 鉛直混合が顕著で鉛直差はほとんどみられない。 
Table 1. The landings at Nagasaki Fish Market by purse-seine boats from the East China Sea.

\begin{tabular}{|c|c|c|c|c|c|c|}
\hline \multirow{2}{*}{ Month } & \multicolumn{2}{|c|}{1958} & \multicolumn{2}{|c|}{1959} & \multicolumn{2}{|c|}{1960} \\
\hline & $\begin{array}{c}\text { No. of } \\
\text { Fishing units }\end{array}$ & $\begin{array}{c}\text { Landings } \\
\text { (ton) }\end{array}$ & $\begin{array}{l}\text { No. of } \\
\text { Fishing units }\end{array}$ & $\underset{\text { (ton) }}{\text { Landings }}$ & $\begin{array}{c}\text { No. of } \\
\text { Fishing units }\end{array}$ & $\begin{array}{l}\text { Landings } \\
\text { (ton) }\end{array}$ \\
\hline Jan. & - & - & - & - & 47 & 1482.0 \\
\hline Feb. & - & - & $\therefore$ & - & 248 & 8125.5 \\
\hline Mar. & 2 & 60.0 & 130 & 2571.2 & 290 & 8192.1 \\
\hline Apr. & 49 & 865.2 & 241 & 6405.5 & 167 & 3689.4 \\
\hline May. & 69 & 1674.9 & 183 & 4792.1 & 5 & 195.0 \\
\hline June & 5 & 32.3 & 39 & 3990.8 & - & - \\
\hline July & - & - & - & - & - & - \\
\hline Aug. & - & - & - & - & - & - \\
\hline Sep. & - & - & - & - & 31 & 975.8 \\
\hline Oct. & - & - & 36 & 1317.0 & 40 & 1334.0 \\
\hline Nov. & - & - & 101 & 3107.3 & 93 & 3330.5 \\
\hline Dec. & - & - & 88 & 2613.0 & 55 & 1536.0 \\
\hline
\end{tabular}

Table 2. The catches of purse-seine boats in the East China Sea by species.

\begin{tabular}{l|r|r|r|r}
\hline \multicolumn{1}{c|}{ Year } & \multicolumn{2}{|c|}{1958} & \multicolumn{2}{c}{1959} \\
\hline Total catch & 6717 & 100 & 43358 & 100 \\
& & & & \\
\hline Jack mackerel & 5210 & 78 & 28172 & 65 \\
Mackerel & 1452 & 22 & 14630 & 34 \\
Scad & 27 & 0 & 362 & 1 \\
\hline
\end{tabular}

Table 3. The surface water temperature and chlorinity in the purse seine fishing grounds.

\begin{tabular}{l|l|c|c}
\hline \multicolumn{1}{c|}{ Period } & $\begin{array}{c}\text { Fishing } \\
\text { Grounds }\end{array}$ & $\begin{array}{c}\text { Water } \\
\text { tempera- } \\
\text { ture }\end{array}$ & Chlorinity \\
\hline $\begin{array}{l}\text { 2nd ten-days, } \\
\text { May. '58 }\end{array}$ & $\begin{array}{l}\text { Kuchibi- } \\
\text { no-se }\end{array}$ & $15 \sim 21$ & $17.5 \sim 19.1$ \\
\hline $\begin{array}{l}\text { 1st ten-days, } \\
\text { June '59 }\end{array}$ & $\begin{array}{c}\text { Kaki- } \\
\text { no-se }\end{array}$ & $13 \sim 16$ & $17.8 \sim 18.1$ \\
\hline $\begin{array}{l}\text { 3rd ten-days, } \\
\text { Feb. '60 }\end{array}$ & $\begin{array}{l}\text { Kuchibi- } \\
\text { no-se }\end{array}$ & $17 \sim 19$ & $19.3<$ \\
\hline $\begin{array}{l}\text { 2nd ten-days, } \\
\text { Jan. '61 }\end{array}$ & " & $17 \sim 18$ & $19.2<$ \\
\hline $\begin{array}{l}\text { 2nd ten-days, } \\
\text { Feb. '61 }\end{array}$ &, & $16 \sim 17$ & $19.1 \sim 19.2$ \\
\hline
\end{tabular}

とした山田 ${ }^{5)}$ ○結果とほぼ一致している。

\section{3. 吉網漁場の海洋構造}

クチビノセ海域における1958 年5月中旬の漁況 と海況゙との閔係を Fig. 1, Table 4 に示した。 の赫期のまき網漁場洁 Fig. 1, Table 4 によると,

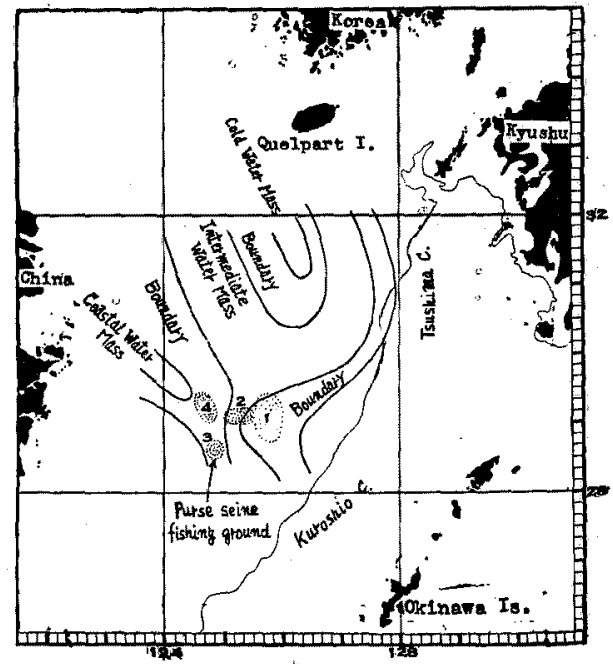

Fig. 1. Hydrographic structure and the distribution of the purse seine fishing grounds in the East China Sea, May. 1958. Dotted areas show the fishing grounds.

\footnotetext{
*我塊分析は T-Cl diagram による。
} 
Table 4. Fishing conditions and hydrographic conditions the sea area near Kuchibi-no-se Bank in the middle of May. 1958.

\begin{tabular}{|c|c|c|c|c|c|c|c|c|}
\hline $\begin{array}{c}\text { Number of } \\
\text { the } \\
\text { operated } \\
\text { position }\end{array}$ & $\begin{array}{l}\text { Date of } \\
\text { operation }\end{array}$ & $\begin{array}{l}\text { Number of } \\
\text { statistical } \\
\text { quadrate }\end{array}$ & $\begin{array}{l}\text { Catch per } \\
\text { unit of } \\
\text { offort } \\
\text { (ton) }\end{array}$ & $\begin{array}{c}\text { Number of } \\
\text { ships in } \\
\text { operation }\end{array}$ & $\begin{array}{c}\text { Water } \\
\text { temperature } \\
\text { ('C) }\end{array}$ & $\begin{array}{l}\text { Vertical } \\
\text { slability }\end{array}$ & $\begin{array}{l}\text { Density } \\
\text { in situ }\end{array}$ & Water mass \\
\hline 1 & May. 13 & 482,483 & 6.0 & 14 & $18 \sim 21$ & $1000 \sim 2000$ & \multirow{4}{*}{$\begin{array}{l}24.00 \\
\sim 24.50\end{array}$} & $\begin{array}{l}\text { Offshore } \\
\text { Front }\end{array}$ \\
\hline 2 & $\begin{array}{ll}" 14 \\
" 15 \\
\end{array}$ & $\begin{array}{c}492 \\
492-3\end{array}$ & $\begin{array}{l}13.5 \\
19.5\end{array}$ & $\begin{array}{l}13 \\
15\end{array}$ & $\begin{array}{l}17 \sim 19 \\
18 \sim 19\end{array}$ & $\begin{array}{c}2000 \\
\prime \prime\end{array}$ & & $\begin{array}{l}\text { Intermediate } \\
\text { water mass }\end{array}$ \\
\hline 3 & 16 & $503-3$ & 28.7 & 13 & $17 \sim 18$ & " & & $\begin{array}{l}\text { Coastal } \\
\text { Front }\end{array}$ \\
\hline 4 & $\begin{array}{ll}* & 17 \\
\prime & 18 *\end{array}$ & $\begin{array}{l}502-7 \\
502-6\end{array}$ & $\begin{array}{r}57.0 \\
6.7\end{array}$ & $\begin{array}{r}14 \\
2\end{array}$ & $\begin{array}{l}15 \sim 16 \\
16 \sim 17\end{array}$ & $\begin{array}{c}2000 \sim 3000 \\
n\end{array}$ & & " \\
\hline
\end{tabular}

*18 日以降蜄林 502 漁区に集結したが，潮流灯付きなど操業条件が悪くなり，漁況は低調になつた。 水温 $15 \sim 21^{\circ} \mathrm{C}$, 塩素量 $17.5 \sim 19.1 \%$ を示す沖合 前線から治岸前線にわたる農林 $482 \cdot 483$ (操澲位置 No. 1) 492 (No. 2) 503 (No. 3) · 502 (No. 4) 漁 区に形成されているが，1夜1統平均漁獾量 10 卜 ン余の好㴔があつたのは中間水塊から大陸沿岸水塊 寄りの海域であつて，中間水塊では 15 トン前後， 沿岸前線厄は約 30 トン, 沿岸前線の5ち, 大陸沿 岸水塊寄りでは約 60 トンの好漁があり，䁔水塊寄り に分布するゴマサバに慗べマアジ成焦分有の重心が 大陸硰岸水塊寄りに存在することが知られ，漁場は 各水塊の集れんした海域に形成されている。Fig. 2 と Table 5 にカキノ七海域に和ける 1959 年 5 月

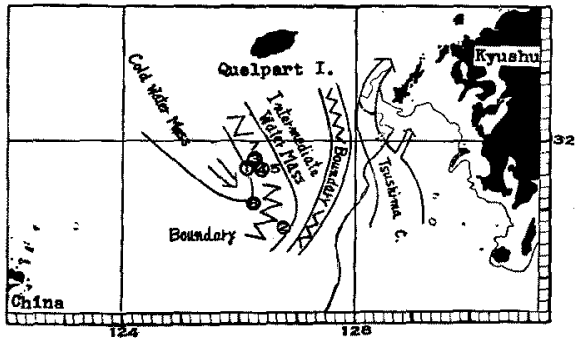

Fig. 2. The hydrographic structure and the distribution of the purse seine fishing grounds. Numerals in the figure show the place where fishing by the purse seine boats was operated, June 1959.

下旬から 6 月上旬の水塊**分布とまき網の漁況を示したが，水塊の分布とまき網漁場との関係名さらに明ら かで, 漁場は黄海冷水塊之中間水塊の接触する沼岸前線の農林 269 (操業位置 No. 2) - 277 (No. 3.4.5. 7) 278 (No.1.6) 漁区に集中している。

Table 5. An example of catches of the purse-sine fishing for the mackerel and jack mackerel operated in June 1959.

\begin{tabular}{|c|c|c|c|c|c|c|c|}
\hline \multirow{2}{*}{$\begin{array}{l}\text { Number } \\
\text { of the } \\
\text { operated } \\
\text { position }\end{array}$} & \multirow{2}{*}{\multicolumn{2}{|c|}{$\begin{array}{l}\text { Date of } \\
\text { operation }\end{array}$}} & \multirow{2}{*}{$\begin{array}{l}\text { Number of } \\
\text { statistical } \\
\text { quadrate }\end{array}$} & \multirow{2}{*}{$\begin{array}{c}\text { Catches in } \\
\text { tons }\end{array}$} & \multirow{2}{*}{$\begin{array}{l}\text { Number of } \\
\text { operations }\end{array}$} & \multicolumn{2}{|c|}{$\begin{array}{c}\text { Species composition } \\
\text { of catches }\end{array}$} \\
\hline & & & & & & $\begin{array}{c}\text { Jack } \\
\text { mackerel }\end{array}$ & Mackerel \\
\hline 1 & June & 2 & $278-9$ & 37.5 & 2 & $100 \%$ & $\%$ \\
\hline 2 & $"$ & 7 & $269-5$ & 30.0 & 1 & 80 & 20 \\
\hline 3 & $"$ & 9 & $277-5$ & 6.0 & 1 & 100 & \\
\hline 4 & " & 9 & $277-3$ & 4.6 & 1 & $"$ & \\
\hline 5 & $"$ & 9 & $277-3.5$ & 6.0 & 1 & $"$ & \\
\hline 6 & $"$ & 9 & $278-6$ & 7.5 & 3 & 90 & 10 \\
\hline 7 & $"$ & 9 & $277-5$ & 10.5 & 1 & 100 & \\
\hline
\end{tabular}

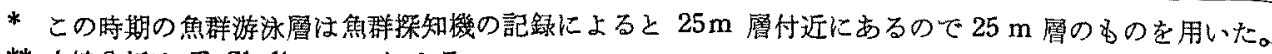

** 承塊分析は T-Cl diagram による。 


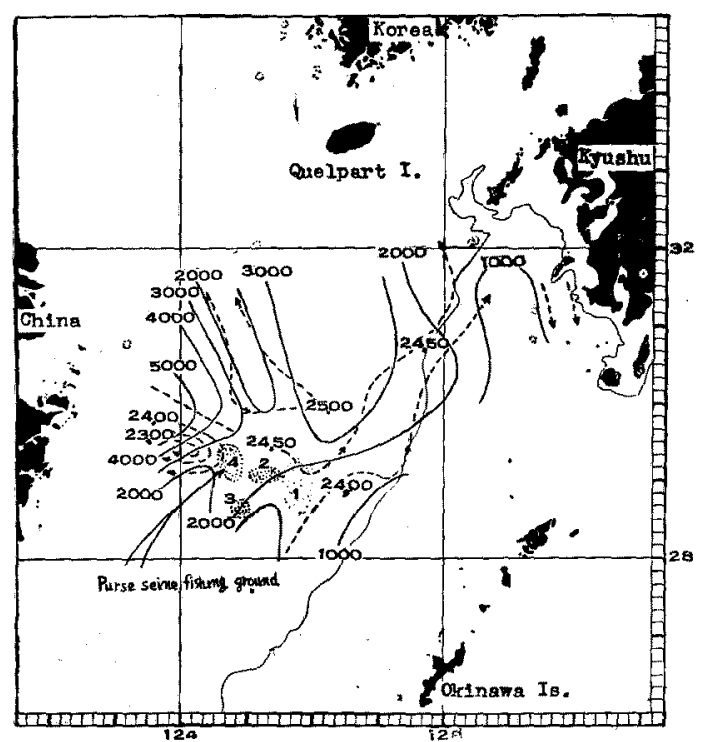

Fig. 3. The distribution of the purse seine fishing grounds in [connection with the vertical stability $(0 \sim 50 \mathrm{~m})$ (solid line) and the Density in situ (mean value of $0 \sim 50 \mathrm{~m}$ ) (dotted line), May 1958 .
Fig. 3 はグチビノセ海域に和ける1958年5 月中甸门鉛㨁安定度 $10^{8} E=\frac{d P \text { st } d}{d z} 10^{8}-500$ $(0 \sim 50 \mathrm{~m})$ 之，現場密度 $10^{2}$ astd $(0 \sim 50 \mathrm{~m})$ の 積算平㚬值の分布を示したものであるが，概観 すると鉛㨁安定度と水塊の分布がよく似て和り 䐘流系水塊の鉛直安定度は 1000 前後, 大垫采

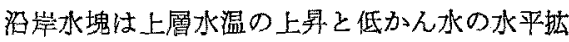
散で成㬝多発達し 3000 余，中間水塊は暖流录 水塊に比べると虔層水の湧年により上屬の鉛直 傾度も比较的急で 2000 前後を示している。ま き絧漁場は図に明らかな上万鉛直安定度の小 さい䁔流系水塊々鉛面安定度の大さ大陸沿岸

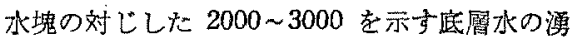
界与る中間水塊から大陸沿宸水塊寄りに形成さ れ，鉛㨁安定度，現場密度の傾度の急な右せえ 珮動の外緑で大漁のあつたことは注目される。

これらのことを概括すると，東支那知に打け るマアジ成算の李網漁場にとつて暖流系水㙕 と才陸系沿岸水塊（黄海冷水塊を含め）の接触 する不連続面が海洋構造上雷要で，刺戟鱼とし て作用寸る各水塊の集えんした中間水塊から大

陸系沿岸水塊奇りの海域が春季のまき絧漁場として䔯値の高いことが知られるが，集れん渦動のみでなく， 発散・沈降渦動について子無関係とは思われない。

\section{要 䄪}

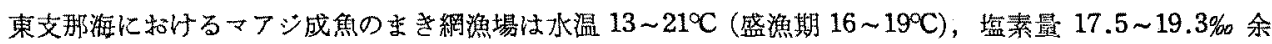

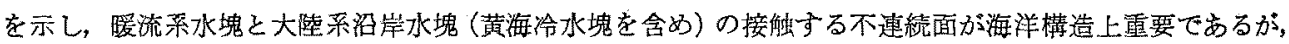

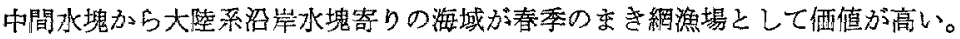

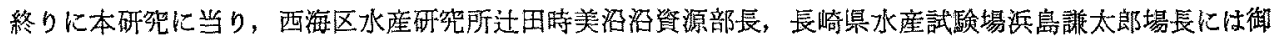

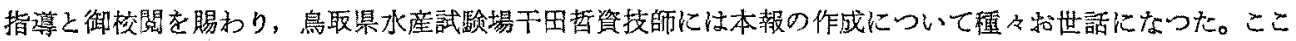

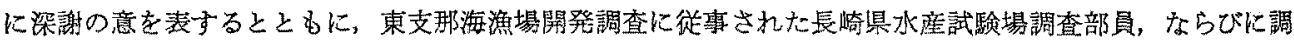
查船鹤丸塨組負諸氏に感謝する。

\section{文献}

1）宇田道隆：対馬䁔流開発謂查報告書（1)，535 537 (1958).

2）江田時美：西海区水研報告，13，1４7 (1957).

3) …_ - — 14, 1 1 41 (1958).

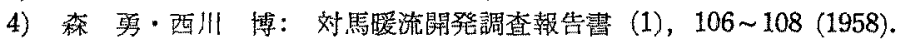

5) 山田鉄雄：対馬䁔流開発調查報告書 (4)，145 175 (1958). 